\title{
PROTEINOGRAMA DO LIQUIDO CEFALORRAQUEANO DO RECEM-NASCIDO PRE-TERMO SADIO
}

\author{
A. SPINA-FRANCA * \\ J. A. LIVRAMENTO ** \\ F. A. C. VAZ*
}

$\odot$ proteinograma do líquido cefalorraqueano (LCR) do recém-nascido a termo sadio apresenta diferenças em relação àquele do adulto. Os princịpais dados da literatura sobre o assunto foram avaliados anteriormente a propósito da análise dos resultados obtidos em estudo sobre o LCR lombar de 40 recémnascidos a termo (RN) cuidadosamente caracterizados quanto à respectiva normalidade e estudados dois dias após o nascimento 7,$8 ; 13$. Em relação ao adulto, foi demonstrado que no $\mathrm{RN}$, normalmente, a concentração proteica total é maior e que é maior a participação no perfil proteico da albumina, das globulinas alfa-1 e das globulinas gama. Em conjunto, o proteinograma do LCR do RN normal é semelhante ao habitualmente descrito em adultos na vigência de certas condições nas quais ocorre comprometimento da barreira hêmatoLCR (BHL). A incompleta maturidade funcional da BHL ao nascimento foi apontada então como a principal responsável pelas características do proteinograma do LCR do RN normal.

Empregando critérios de seleção e métodos de análise laboratorial semelhantes, as caracteristicas gerais do LCR de recém-nascidos pré-termo (RN-PT) foram estudadas posteriormente 14,15. Dos dados evidenciados para RN-PT sadios, interessa mencionar que foi verificado ser significativamente maior a concentração proteica total que entre os $\mathrm{RN}$ a termo sadios. A diferença foi considerada como sendo devida, em especial, ao fato de ser ainda menos diferenciada no RN-PT a BHL que no RN a termo. Essa conclusão está de acordo com as de outros estudos registrados na literatura nos quais o assunto é abordado.

E objeto desta investigação estabelecer as características do proteinograma do LCR, em RN-PT normais, relacionando-as às já mencionadas para o proteinograma do LCR de RN a termo também sadios e estudados mediante métodos semelhantes no mesmo laboratório.

\section{MATERIAL E METODOS}

Foi estudado o proteinograma do LCR lombar no segundo dia de vida de 40 RN-PT. Estes compreendem parte de casuistica analisada em estudo quanto aos caracteres gerais do LCR. Eles nåo apresentavam intercorrências perinatais e nem anormalidades clínicas

Trabalho do Centro de Investigacóes em Neurologia e da Unidade Neonatal do Hospital das Clínicas da Faculdade de Medicina da Universidade de Sao Paulo: Docente Livre; *Médico Assistente. 
ou do exame neurológico na primeira semana de vida, nara os critérios adotados 5,6. A idade gestacional era inferior a 37 semanas em todos os casos (média 33,8; desvio padrăo 2,34) e, em todos, o parto foi năo-traumático. Todos obtiveram notas de 6 a 9 no 59 minuto de vida, segundo avaliaça tipo Apgar 2. O peso foi inferior a $2.700 \mathrm{~g}$ em todos (médía 2.129 g; desvio padráo 285) e o perímetro cefálico foi representado pela média de $31,4 \mathrm{~cm}$ e desvio padrắ de 2,11. As condiçóes sanguíneas no segundo dia de vida, săo representadas pelas estimativas seguintes (média e desvio padrăo): hemoglobina $16,7 \pm 1,89 \mathrm{~g} / 100 \mathrm{ml}$; hematócrito 49,9 $\pm 4,50 \%$; hemácias $5,0 \pm 0,79$ milhơes/mm3; leucócitos 10,4 $\pm 3,65 \mathrm{mil} / \mathrm{mm} 3$; plaquetas $271,1 \pm 70,6 \mathrm{mil} / \mathrm{mm} 3$; pH 7,3 $\pm 0,07 ; \mathrm{pO}_{2} 57,9 \pm 9,83 \mathrm{~mm} \mathrm{Hg} ; \mathrm{pCO}_{2} 38,6 \pm 6,83 \mathrm{~mm} \mathrm{Hg} ; \mathrm{HCO}_{3} 19,9 \pm 2,50 \mathrm{mEq}$ por litro; indice de saturaçăo de $O, 92,7^{2} \pm 4,24 \%$; excesso de bases $5, b^{3} \pm 2,73 \mathrm{mHq} / 1 \mathrm{tro}$; glicemia $60,4 \pm 19,82 \mathrm{mg} / 100 \mathrm{ml} .{ }^{2}$ Săo as seguintes as estimativas da composiçăo da amostra de LCR lombar utilizada na presente investigaçăo (média e desvio padrăo): leucócitos $3,93 \pm 3,57 / \mathrm{mm}^{3}$; hemácias $264 \pm 303 / \mathrm{mm}$; bilirrubina 27,7 $\pm 13,50$ dmicromol/1; hemoglobina (ausente em 26 amostras) 1,1 1 1,69 dmicromol/1; glicose $51,66 \pm 18,14 \mathrm{mg} / 100 \mathrm{ml}$.

O proteinograma do LCR lombar fol estudado no segundo dia de vida, mediante técnica anteriormente especificada, utilizando gel de celulose (Cellogel, Chemotron) como suporte para a eletroforese e os dados obtidos foram comparados aqueles anteriormente registrados para $\mathrm{RN}$ a termo 13: proteinas totais (média 74,3 $\mathrm{mg} / 100 \mathrm{ml}$; desvio padrăo 23,49 e desvio de média 3,76) e fraçós proteicas (percentagem média: pré-albumina 1,0; albumina 58,9; alfa-1 6,2; alfa-2 6,1; beta 10,8; táu 3,2 e gama 13,8).

\section{RESULTADOS}

Constam da tabela 1 os resultados obtidos para cada RN-PT quanto a concentracăo proteica total e ao respectivo perfil proteico.

As estimativas da concentração proteica total săo as seguintes: média de I44,6 $\mathrm{mg} / 100 \mathrm{ml}$; desvio padrăo 40,12; desvio da média 6,24. O limite superior calculado yara as variacóes na amostra é $226 \mathrm{mg} / 100 \mathrm{ml}$ e o inferior, 63 (para $t=5 \%$ ). Em relagón as estimativas dos RN normais verifica-se ser significativa a diferença entre as médias $(t=2,16)$ e evidente a maior dispersăo dos resultados. Dos $40 \mathrm{RN}-\mathrm{PT}, 10$ apresentavam concentraçăo proteica total dentro do esperado para um $R N$ normal e os restantes, acima.

Săo os seguintes os valores médios para a participaça de cada fraça no perfil proteico, para as 40 amostras estudadas: pre-albumina 4,26\%; albumina $59,28 \%$ aifa-1 4,51\%; alfa-e 5,48\%; beta 11,23\%; tdu 1,63\%; gama 13,61\%. Os limites máximo e minimo observados para cada fraça proteica foram respectivamente para: pré-albumina 6,2 e 2,0\%; albumina 68 e 51\%; alfa-1 7,0 e 2,0\%; alfa-8 9,4 e 3,1\%; beta 14,9 e 6,3\%; tdu 7,4 e $0 \%$; gama 19,1 e 6,8\%.

A fraçăo táu nåo se apresentou suficientemente diferenciada no perfil proteico em 25 amostras (62,5\%); no $\mathrm{RN}$ a termo sadio o mesmo fato foi observado em 7 de 40 amostras $(\mathbf{1 7}, 5 \%)$.

Inversăo alfa-1/alfa-2 no perfil proteico foi observada em 5 amostras (12,5\%). No RN a termo sadio essa inversăo ocorreu em 21 dos 40 casos (52,5\%).

Em conjunto, os perfis proteicos observados podem ser considerados do "tipo misto" preferencialmente, isto é, como se perfis LCR e sangue fossem misturados de modo variável. O comportamento da fraçăo táu, a participaçăo da albumina no perfil e a pequena ocorrência de inversắo alfa-1/alfa-2 săo os dados principaís ao considerar 0 conjunto perfil tipo misto para os casos estudados.

\section{COMENTARIOS}

O grupo de RN-PT analisado é comparável ao de RN a termo anteriormente estudado, por terem sido semelhantes os critérios utilizados para a carac- 


\begin{tabular}{|c|c|c|c|c|c|c|c|c|}
\hline \multirow{3}{*}{ Caso } & \multirow{3}{*}{$\begin{array}{l}\text { Proteinas } \\
\text { totais } \\
(\mathrm{mg} / 100 \mathrm{ml})\end{array}$} & \multirow{3}{*}{$\begin{array}{l}\text { Pré-al- } \\
\text { bumina }\end{array}$} & \multicolumn{6}{|c|}{ Fraçס̄es proteicas (\%) } \\
\hline & & & \multirow{2}{*}{$\begin{array}{l}\text { Albu- } \\
\text { mina }\end{array}$} & \multicolumn{4}{|c|}{ Globulinas } & \multirow[b]{2}{*}{ gama } \\
\hline & & & & alfa-1 & alfa-2 & beta & táu & \\
\hline 01 & 144 & 4,9 & 61 & 6.7 & 4,3 & 14,0 & & 9,1 \\
\hline 02 & 122 & 4,1 & 57 & 4,1 & 4,9 & 9,0 & 4,1 & 16,8 \\
\hline 03 & 180 & 6,2 & 69 & 3,1 & 3.1 & 6,3 & 1,9 & 10,4 \\
\hline 04 & 156 & 5,8 & 63 & 4,9 & 5,9 & 6,9 & 4,9 & 8,6 \\
\hline 05 & 52 & 5,3 & Б3 & 5.7 & 5,3 & 8,8 & 5,3 & 16,6 \\
\hline 06 & 140 & 4,1 & 51 & 6,0 & 9,4 & 9,4 & 4,7 & 15,4 \\
\hline 07 & 67 & 5,9 & 54 & 4,0 & 5.0 & 10,9 & 7,4 & 12,8 \\
\hline 08 & 116 & 4,4 & 53 & 5,8 & 5,8 & 13,3 & 4,4 & 13,3 \\
\hline 09 & 196 & 5,6 & 51 & 2,0 & 4,5 & 13,8 & 6,1 & 17,0 \\
\hline 10 & 152 & 5,2 & 62 & 5,0 & 6,0 & 14,9 & & 16,9 \\
\hline 11 & 170 & 4,7 & 54 & 6.1 & 4,6 & 14,3 & & 16.3 \\
\hline 12 & 164 & 4,6 & 57 & 4,7 & 4,8 & 12,4 & & 16,5 \\
\hline 13 & 200 & 4,3 & 52 & 4,3 & 8.7 & 14,3 & & 16,4 \\
\hline 14 & 98 & 4,4 & 57 & 4,4 & 7,9 & 9,9 & $\mathbf{3 , 5}$ & 12,9 \\
\hline 15 & 144 & 4,2 & 64 & 3,1 & 5,0 & 11,8 & & 11,9 \\
\hline 16 & 94 & 4,5 & 67 & 3,2 & 3.9 & 11,7 & & 9,7 \\
\hline 17 & 196 & 3,1 & 68 & 3,1 & 3,1 & 8,1 & & 14,6 \\
\hline 18 & 92 & 4,4 & 61 & 6,0 & 6,0 & 11,3 & & 11,3 \\
\hline 19 & 152 & 5,4 & 62 & 5.4 & 6.5 & 10,9 & & 9,8 \\
\hline 20 & 152 & 3,9 & 56 & 4,3 & 6,2 & 11,7 & 4,3 & 13,6 \\
\hline 21 & 94 & 3,8 & 61 & 3,1 & 5,3 & 13.0 & & 13,8 \\
\hline 22 & 200 & 4,9 & 65 & 3,2 & 5,4 & 10,7 & & 10,8 \\
\hline 23 & 210 & 4,7 & 51 & 7,0 & 7,4 & 10,7 & 4,7 & 14,5 \\
\hline 24 & 98 & 3,4 & 68 & 3,4 & 4,8 & 10,9 & & 9,5 \\
\hline 25 & 152 & 2,4 & 66 & 4,1 & 3.6 & 11,2 & & 12.7 \\
\hline 26 & 170 & 2,0 & 58 & 3,6 & 7,1 & 12,0 & 5,3 & 12,0 \\
\hline 27 & 100 & 5,4 & 59 & 4,3 & 5,4 & 14,6 & & 11,3 \\
\hline 28 & 116 & 4,6 & 63 & 4,8 & 3,9 & 11,6 & & 12,1 \\
\hline 29 & 136 & 4,7 & 56 & 4,7 & 6.1 & 12,1 & 2,3 & 14,1 \\
\hline 30 & 122 & 2,5 & 61 & 4,1 & 7,1 & 9,6 & & 15,7 \\
\hline 31 & 188 & 4,7 & 65 & 2,9 & 4.7 & 9,9 & & 12,8 \\
\hline 32 & 200 & 2,8 & 67 & 4,5 & 4,5 & 6,7 & & 14,5 \\
\hline 33 & 116 & 4,4 & 61 & 5,0 & 5,9 & 9,9 & & 13,8 \\
\hline 34 & 128 & 4,6 & 52 & 6,6 & 6,6 & 13,3 & 3,3 & 13,6 \\
\hline 35 & 188 & 4,0 & 56 & 4,0 & 4,0 & 12,9 & & 19,1 \\
\hline 36 & 142 & 2,4 & 63 & 3,9 & 4,9 & 11,2 & & 14,6 \\
\hline 37 & 122 & 5,0 & 58 & 3,8 & 7,5 & 12,7 & & 13,0 \\
\hline 38 & 170 & 2,9 & 64 & 4,7 & 4.7 & 9,9 & & 13,8 \\
\hline 39 & 144 & 2,8 & 62 & 4,3 & 3,1 & 10,5 & 3,1 & 14,2 \\
\hline 40 & 200 & 3,4 & 53 & 6,4 & 6,4 & 12,4 & & 18,4 \\
\hline Média & 144,6 & 4,26 & 59,28 & 4,51 & 5,48 & 11,23 & 1,63 & 13,61 \\
\hline
\end{tabular}

Tabela 1 - Proteinograma do LCR dos to recem-nascidos prematuros normais estudados 8 respectivos valores médios. 
terização da normalidade respectiva. Tratando-se de RN sadios e tendo sido o proteinograma estudado de modo semelhante, é possível comparar os resultados entre si, bem como considerá-los representativos da faixa etária em condições de nascimento diverso. Assim sendo, verifica-se ser significativamente maior a concentração média de proteínas totais no RN-PT. Por outro lado, distribuem-se no perfil proteico as frações de modo diverso: no RN-PT configuram, em média, perfil tipo misto, enquanto que nos $\mathrm{RN}$ a termo configuram, também em média, perfil tipo transudativo. Dado o nível de dispersão observado, limites máximo e mínimo da participação de cada fração no perfil proteico não oferecem dados significativos quanto a diferenças. Por essa razão, não devem ser considerados orientativos para julgar da prematuridade ou não, em dado caso. Todavia, è de notar que: a ausência do agrupamento táu das globulinas beta é mais comum no RN-PT que no RN a termo (3,6/1); a inversão alfa-1/alfa-2 é mais comum no RN a termo que no RN-PT $(4,2 / 1)$.

A ausência de atividade da BHL iria permitir evidenciar um perfil de tipo sérico, isto é, semelhante ao encontrado no soro do RN ${ }^{16}$. Em nenhum caso o perfil se comportava dessa forma. Os perfis tipo misto, tipo transudativo e tipo albumínico indicam graus de intensidade respectivamente maior ou menor da atuação parcial da BHL. Nesse sentido, eles se interpõem, portanto, entre o perfil tipo sérico e o perfil tipo LCR, este último próprio à atuação efetiva da BHL no que tange às proteínas presentes no LCR. Esses aspectos sugerem que, ao nascimento, a imaturidade da BHL no RN-PT seja mais expressiva que no RN a termo.

Dadas as diferenças na composição do LCR quando comparados RN nascidos par cesárea ou por parto normal ${ }^{10}$, poder-se-ia considerar a hemorragia própria ao trauma de parto como condição hábil à produção de alterações proteicas que induziriam um perfil tipo misto. Embora concorrendo em número maior que no RN a termo, o número de hemácias no LCR dos RN-PT analisados não é de ordem a levar a modificações significativas do perfil proteico. Assim sendo, resta como hipótese para explicar os aspectos peculiares das proteinas do LCR no RN-PT a imaturidade da BHL, como no RN a termo.

De fato, são geralmente atribuídas à imaturidade da BHL as caracteristicas do LCR no RN, consoante analisado anteriormente, embora não haja demonstração definitiva nesse sentido, mesmo do ponto de vista experimental ${ }^{11}$. Um dos argumentos analisados quanto à mencionada imaturidade da BHL está relacionado às diferenças entre a composição do LCR no RN-PT em relação à do RN a termo. Destacam-se, nesse sentido, a maior concentração de heme-pigmentos e de proteinas no LCR-PT ${ }^{4}$. São inversamente proporcionais a intensidade da hiperproteinorraquia e o baixo peso do RN-PT, não indicando as mais elevadas concentrações proteicas vigência de um acometimento do sistema nervoso central do qual pudesse decorrer um comprometimento da BHL ${ }^{\text {. }}$. As diferenças no que tange ao perfil proteico podem ser explicadas pela imaturidade dos sistemas relacionados à passagem de proteinas plasmáticas para o LCR, como os de ultrafiltração, e pela imaturidade de sistemas enzimáticos ${ }^{1,12}$. Decorrem destes últimos peculiaridades de certas fraçōes proteicas do LCR, como a diferenciação do subgrupo táu das globulinas beta. No RN, e especialmente no 
RN-PT, esses sistemas parecem encontrar-se incompletamente diferenciados, dai podendo decorrer em parte a concentração pequena ou nula dessa fração proteica no $L C R$ respectivo ${ }^{3}$.

\section{RESUMO}

Foram estudadas a concentração proteica total e o perfil proteico de 40 RN-PT sadios. Os resultados encontrados foram comparados àqueles obtidos para $40 \mathrm{RN}$ a termo igualmente sadios, selecionados segundo critérios semelhantes, cujo LCR foi analisado mediante os mesmos métodos e no mesmo laboratório. Os dados obtidos confirmam ser, em média, a concentração proteica total superior no RN-PT que no RN a termo e a diferença encontrada foi estatisticamente significativa. $O$ perfil proteico mostrou-se, em média, também diverso. As diferenças encontradas permitiram caracterizá-lo como de "tipo misto", sendo salientada a ausência frequente da sub-fração táu.

\section{SUMMARY}

\section{Cerebrospinal fluid proteins in the premature newborn infant.}

The total protein concentration and the protein profile were studied in 40 healthy premature newborn infants at the second day of life. The results were compared to those obtained for 40 full-term healthy newborn infants. Results pertinent to this last group were reported previously.

Results here reported confirm that there is a higher total protein concentration in the cerebrospinal fluid of the premature newborn infant. Statistical analysis shows that the difference is significant $(t: 2.16)$

The mean protein profile shows a protein fractions distribution proper to the "mixed profile type". The absence of tau-fraction was the most commonly finding observed in this way.

Data were compared to those reported in the literature, and they were also considered proper to immaturity conditions of blood brain barrier.

\section{REFERENCIAS}

1. ADINOLFI, M.; BECK, S. E. HADDAD, S. A. \& SELLER, M. J. - Permeability of the blood-cerebrospinal fluid barrier to plasma proteins during foetal and perinatal life. Nature $259: 140,1976$.

2. APGAR, V. \& JAMES, L. S. - Further observations on the newborn scoring system. Amer. J. Dis. Child. 104:419, 1962.

3. BARTOLOZZI, G.; CIAMPOLINI, M.; MARIANELLI, L. \& FRANCHINI, F. Studio delle proteine liquorali nel prematuro: I - Ricerche electtroforetiche; II - Ricerche immunoelettroforetiche. Riv. Clin. pediatr. 80:296 e 595, 1967.

4. BAUER, C. H.; NEW, M. I. \& MILLER, J. M. - Cerebrospinal fluid protein values of premature infants. J. Pediat. $66: 1017,1965$.

5. DUBOWITZ, L. M. S.; DUBOWITZ, V. \& GOLDBERG, B. A. - Clínical assesment of gestational age in the newborn infant. $J$. Pediat. 77:1, 1970. 
6. FARR, V. - Estimation of gestational age by neurological assesment in first week life. Arch. Dis. Childh. 43:353, 1968.

7. LIVRAMENTO, J. A.; LUZ, B. R.; HAUSSEN, S. R. \& SPINA-FRANÇA, A. Citomorfologia do líquido cefalorraqueano do recém-nasoido normal. Arq. NeuroPsiquiat. (São Paulo) 32:207, 1974.

8. LUZ, B. R. - Composição do liquido cefalorraqueano do recém-nascido normal. Arq. Neuro-Psiquiat. (São Paulo) 33:200, 1975.

9. NEW, M. I. \& BAUER, C. H. - The prognostic significance of a markedly elevated cerebrospinal fluid protein in premature infants. Amer. J. Dis. Child. 100:618, 1960.

10. PARRA, M. \& MUXICA, R. - Fl liquido cefaloraquideo en los recién-nacidos. Rev. Neurol. (Chile) 5:7, 1956.

11. SARF, L. D.; PLATT, L. H. \& McCRACKEN Jr., G. H. - Cerebrospinal fluid evaluation in neonates: comparison of high-risk infants with and without meningitis. J. Pediat. 88:473, 1976.

12. SIEMES, H.; SIEGERT, M. \& RATING, D. - Das Liquorproteinprofile normale Kinder und seine Abhängingkeit von Lebensalter. Untersuchungen mittels CAF und Agarosegel Elektrophorese. Neuropaed. 6:383, 1975.

13. SPINA-FraNÇA, A.; LUZ, B. R. \& HAUSSEN, S. R. - Proteinograma do liquído cefalorraqueano do recém-nascido normal. Arq. Neuro-Psiquiat. (S\&̊o Paulo) 32:212, 1974.

14. Vaz, F. A. C.; Livramento, J. A. \& SPINA-Franç, A. - Composición del liquido cefalorraquídeo del recién nacido pretérmino. Bol. méd. Hosp. infant. (México) $34: 1135,1977$.

15. VAz, F. A. C.; LIVRAMENTO, J. A. \& SPINA-FRANCA, A. - Liquido cefalorraqueano no recém-nascido pré-termo adio. Arq. Neuro-Psiquiat. (S\&̊ Paulo) 35: $183,1977$.

16. VIEIRA, P. B. - Contribuiçăo ao estudo das proteinas séricas no recém-nascido pela eletroforese em papel. An. Matern. Såo Paulo 46:183, 1958.

Centro de Investigaç8s em Neurologia da FMUSP - Caixa Postal 5199 - 0100a são Paulo, SP - Brasil. 